\title{
Rotavirus Disease Burden and Molecular Epidemiology in Children with Acute Diarrhoea Age Less than 5 Years in Nepal
}

\author{
Sherchand JB ${ }^{1}$, Cunliffe $\mathrm{NA}^{2}$, Tandukar $\mathrm{S}^{3}$, Yokoo $\mathrm{M}^{4}$, Pandey BD ${ }^{5}$, Niraula $\mathrm{P}^{6}$, Panta $\mathrm{AR}^{7}$, Nakagomi $\mathrm{O}^{8}$ \\ ${ }^{1}$ Dr. Jeevan B. Sherchand, MScTrop Med (Bkk); Ph.D.(UK), Professor in Medical Microbiology, Tribhuvan University \\ Institute of Medicine, Chief of Public Health Research Laboratory, Maharajgunj Medical Campus, Kathmandu, Nepal, \\ ${ }^{2}$ Dr. Nigel A. Cunliffe, MBChB; MRCP; Ph.D.(UK), Assoc. Professor and Head, Department of Medical Microbiology \\ and Genitourinary Medicine, University of Liverpool, UK, ${ }^{3}$ Sarmila Tandukar, MSc, Microbiologist, Public Health \\ Research Laboratory, Tribhuvan University Institute of Medicine, Maharajgunj, Nepal, ${ }^{4}$ Dr. Michiyo Yokoo, Ph.D., \\ Lecturer, Department of Molecular Microbiology and Immunology, Graduate School of Biomedical Sciences, Nagasaki \\ University, Japan, ${ }^{5}$ Dr. Basu Dev Pandey BD, MD; Ph.D., ${ }^{4}$ Sukra Raj Tropical and Infectious Disease hospital, Teku, \\ Nepal, ${ }^{6}$ Dr. Purushottam Niraula, MBBS, MD Senior Pediatrician, Kanti children Hospital, Maharajgunj Kathmandu, \\ Nepal (Deceased), 'Dr. Arjun Raj Panta, MBBS; DCH; M.Paed.(UK), Sen. Pediatrician, Kanti children Hospital, \\ Maharajgunj Kathmandu, Nepal, ${ }^{8}$ Dr. Osamu Nakagomi, MD; Ph.D., Professor, Department of Molecular Microbiology \\ and Immunology, Graduate School of Biomedical Sciences, Nagasaki University, Japan.
}

Address for correspondence: Dr. Jeevan B. Sherchand, E-mail: jeevansherchand@hotmail.com

\begin{abstract}
Introduction: Rotavirus is the most common cause of severe gastroenteritis in infants and young children worldwide. The aim of the study was to determine rotavirus disease burden and distribution of rotavirus genotypes in children less than five years of age. Methodology: Stool samples were collected from 1768 hospital admitted children under 5 years of age with acute watery diarrhea during November 2005 to October 2008. Rotavirus in stool samples was detected by Enzyme Immuno Assay (EIA) and positive specimens for rotavirus positive was genotyped by reverse transcription-polymerase chain reaction (RTPCR) and sequencing methods. Results: The prevalence of rotavirus was $36.59 \%$ (647/1768). Detection was higher in male (33.3\%) than female (26.9\%). The prevalence was higher during the month of January (2005-06) and February in other periods. During 2005-06, high prevalence of rotavirus was noted in children of age between 6-11 months while in 2006-07 and 2007-08 high prevalence was seen in age group 12-23 months. The most common genotyping of rotavirus identified $5 \mathrm{G}$ types and $3 \mathrm{P}$ types. Genotypes G12 and P [8] were most common during both periods studied (G12; 50\%, 29\% $33.7 \%$ in 2005-06, 2006-07 and 2007-08 respectively and P[8]; 47\%, 35\% and 43.5\% in 2005-06, 2006-07 and 2007-08 respectively). Among six combined genotypes, G12P [6] was most prevalent (34\%, 24\% and 47.5\% in 2005-06, 2006-07 and 2007-08 respectively) where as G1P [6] (4\%) was seen in year 200708 only. Conclusions: The study demonstrates the burden of rotavirus diarrhea in Nepal. The data on rotavirus genotypes will help inform decisions as to whether rotavirus vaccine should be considered for inclusion in to Nepal's National Immunization Program.
\end{abstract}

Key words: Rotavirus, Diarrhea, Genotyping, Children

\section{Introduction}

A global estimate suggests that $19 \%$ of total child deaths are attributable to diarrhoea and $73 \%$ of these deaths are concentrated in 15 developing countries. It is the second commonest cause of death due to infectious diseases in children under five and also a major cause of adult death in such countries ${ }^{1-2}$. Rotavirus remains 
the most common cause of severe, dehydrating diarrhoea among children worldwide ${ }^{3-5}$. It is estimated to be responsible for more than 600,000 deaths per year in these children with $85 \%$ occurring in low-income countries ${ }^{3}$.

The study done by Nepal Human Development Report published in 1998,16 to $25 \%$ of childhood deaths occur due to diarrhoea. A study of travelers and foreign residents reported an incidence of Rotavirus in $8 \%$ of cases. Group C Rotavirus infection was demonstrated from convalescent sera in patients with diarrhoea by others ${ }^{6}$. They primarily spread by the feco-oral route. Symptoms include diarrhoea, vomiting and fever. In severe cases acidosis, electrolyte abnormalities, severe dehydration and death can occur. Infection can be asymptomatic, especially in infants aged less than three months. Diagnosis is usually confirmed by detection of rotavirus in stool samples ${ }^{4}$. Rotavirus infects the proximal small intestine, where it elaborates an enterotoxin and destroys the epithelial surface, resulting in blunted villi, extensive damage, and shedding of massive quantities of virus in stool. The estimated incubation period for rotavirus diarrheal illness is $<48$ hours $^{4}$. The virus was discovered 30 years ago. It consists of 11 double-stranded RNA segments encased in a bilayered capsid containing three viral proteins (VP4, VP6 and VP7) ${ }^{6}$. These proteins, which are infective and induce an immune response in the host, are the basis of the classification system used today. VP6 determines the group and subgroup, while VP4 is indicative of type $P$, and VP7 is associated with type G. The variations in these viral proteins have an impact on immunity, the methods used for detection, and effective vaccine development ${ }^{7}$.

Since, Nepal is one of the developing countries and more people inhabit are illiterate and have poor economical status, children death even today occur due to diarrhoea. The study therefore is aimed to determine rotavirus disease burden and distribution of rotavirus genotypes in hospitalized children less than five years of age.

\section{Materials and methods}

This study was carried out between November 2005 to October 2008 in Tribhuvan University Teaching Hospital, Institute of Medicine, Public Health Research Laboratory, Maharajgunj, Kathmandu. A total of 1768 stool samples from children's hospital were collected from patients exhibiting symptoms of acute watery diarrhea having vomiting and abdominal pain after informed parental consent. All case based data and clinical information was recorded on a standardized questionnaire and entered into EPI-Info computer based analysis software.

\section{Detection Rotavirus by EIA}

Stool samples were analyzed for rotavirus by using Premier Rotaclone which is Enzyme Immunoassay EIA (Meridian Bioscience, USA) for the detection of rotavirus antigen in human fecal samples according to the instructions of the manufacturer. All EIA positive samples were subsequently confirmed by Reverse Transcription-Polymerase Chain Reaction (RT-PCR). Rotavirus positive samples were frozen at $-70^{\circ} \mathrm{C}$ until genotyping of rotavirus strains processed.

\section{Rotavirus Genotyping}

Detection of rotaviruses in clinical specimens and determination of the G-types and P-types can be accomplished by extraction of the viral RNA from fecal specimens and analysis by reverse-transcription polymerase chain reaction (RT-PCR) with primers specific for the VP7 genes of G serotypes 1,2,3,4, 8 and 0 and VP4 genes of P serotypes 4, 6, 8, 9, 10 and 11 . in the study for rotavirus strain identification rotavirus positive samples were transported to the Department of Medical Microbiology, Liverpool University where RT-PCR amplification were used according the method for genotyping method described by Gouvea et al and Gentsch et $\mathrm{al}^{7,8}$.

\section{Results}

A total of 1768 children were enrolled in between three years study (November 2005-2008) period that fulfill the enrollment criteria for the study. Of them 647 $(36.59 \%)$ cases were positive for rotavirus by EIA, among the positive cases, 480 samples were carried out genotyping by RT-PCR.

\section{Distribution of rotavirus by EIA}

Rotavirus detection by EIA was 37.01\% (268/724), $35.64 \%(195 / 547)$ and $37.02 \%(184 / 497)$ in the year 2005-2006, 2006-2007 and 2007-2008 respectively.

\section{Year and month wise distribution of rotavirus positive on hospitalized children:}

Though the infection occurred all year round; but the prevalence trend was higher in winter season (Fig 1). The seasonal and monthly frequency of isolation of rotavirus in hospitalized children was found to be highest from December to March which did not differ substantially between the years of the study. A majority of positive cases occurred in January; 57\% (61/106), $62.5 \%(20 / 32)$ and $57.14 \%(24 / 42)$ in year 2005-06, 2006-07 and 2007-08 respectively (Fig 1). 


\section{Age distribution of rotavirus positive children whom were hospitalized}

The highest prevalence was seen in children from 3 to 23 months of age which was shown in below (figure 2). In all three years i.e. from November 2005 to October 2006, November 2006 to October 2007 and November 2007 to October 2008. The distribution of rotavirus among various age groups indicated that the highest number was found in age group 3-23 months. Age wise distribution showed that the infection rate was found to be highest in age group 6-11 months holding $51.24 \%$, followed by age group $3-5$ months $(42.5 \%)$ in year $2005-06$ similarly $12-23$ months $(46.4 \%)$ followed by age groups $3-5$ months (44.4\%) in year 2006-07 and in year 2007-08, age group between 6-23 months showed highest rate of infection holding same positive percentage i.e.39\%. This showed that rotavirus positive cases increasing slowly from age 3 months and decreasing after 23 months except in year 200607 where rotavirus positive was found to be highest in age group 12-23 months. The percentage of positive cases was shown in figure 2 . From the figure the highest prevalence of rotavirus was seen in children age group between 6-11 months in the year 2006-2007, while the highest prevalence of rotavirus was seen in children age group between 12-23 months in the year 2005-2006 and 2007-2008. Lowest positive cases were seen in children between 0-2 months and 24-60 months in all periods. The positive rate was declined after 12-23 months for all periods.

\section{Rotavirus genotyping}

Distribution of $\mathrm{G}$ types among rotaviruspositive specimens from hospitalized children between 2005 and 2008

The $\mathrm{G}$ genotype $\mathrm{G} 12$ was predominant in all periods; 2005-06 (50\%) and 2006-07 (29\%) and 2007$08(33.7 \%)$ studied (Table 1). Second most common G genotypes in 2005-06 were G1 while G9 was most common in 2006-07 and 2007-08. G2, G3 genotypes were also identified in all periods. Some strains were non-typable in 2005-06 (4\%) 2006-07 (9\%) and 2007-08 (7\%). The most prevalent $\mathrm{G}$ type during the study period was $\mathrm{G} 12$ accounting for $50 \%$ of typed strains in $2005-06$, $33.7 \%$ in $2007-08$ and $29 \%$ in $2006-07$, followed by G1 (26\%) in 2005-06, G9 (28\%) and G2 (20\%) in 2006-07 and G9 (22.8\%) and G1 (17.8\%) as shown in table (1).

\section{Distribution of rotavirus $P$ types among rotavirus-positive in hospitalized children}

Of the three different P-types, P[8] was predominant i.e. $47 \%, 35 \%$ and $43.5 \%$ followed by P[6] i.e. $37 \%, 33 \%$ $27.7 \%$ respectively in all year 2006-2008 as shown in table (2). Some strains were non-typable in 2005-06 (4\%) and 2006-08 (8\%); and some were mixed in 200506 (2\%), 2006-07 (1\%) and 2007-08 (2\%) respectively.

Distribution of major combination of $G$ and $P$ types among rotavirus-positive specimens of hospitalized children.

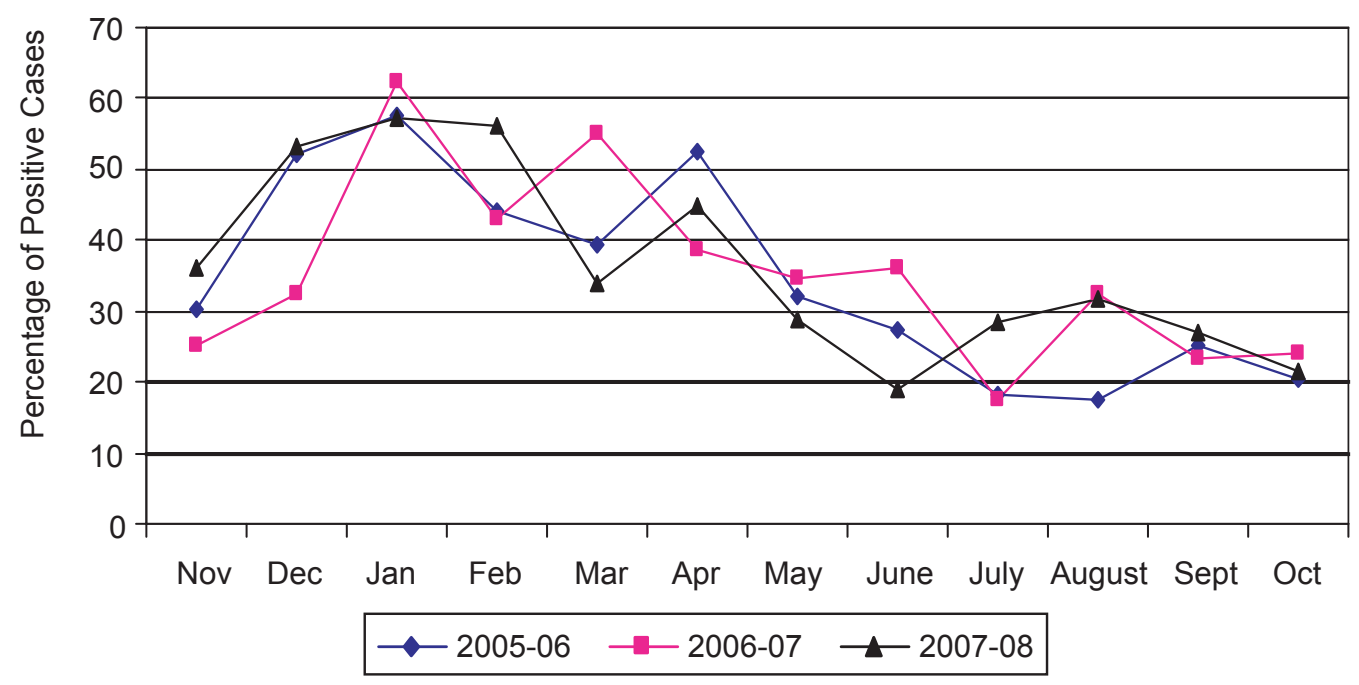

Fig 1: Year and month distribution of rotavirus 


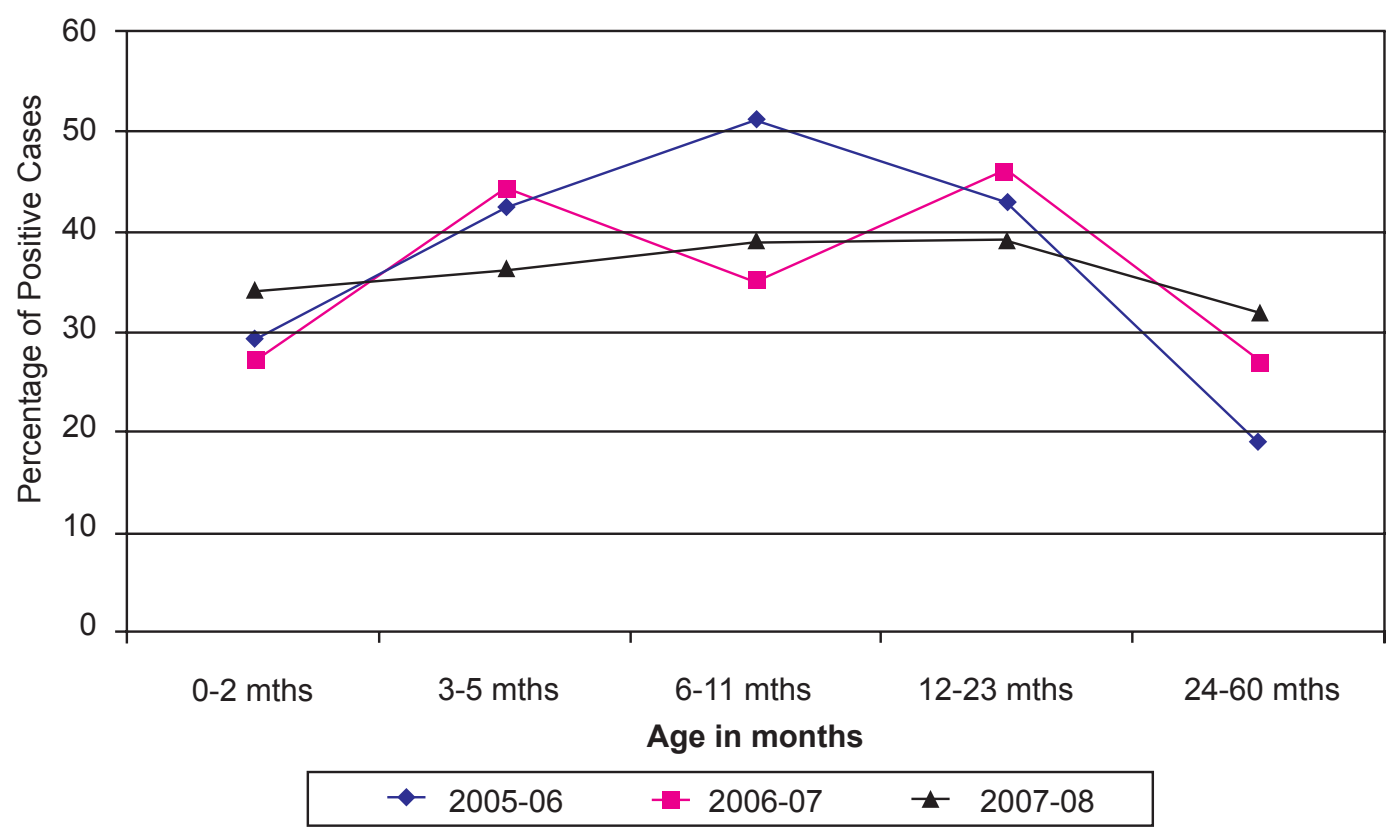

Fig 2: Age-wise distribution of rotavirus

Table 1: Distribution of $G$ types among rotavirus-positive specimens from hospitalized children between 2005 and 2008

\begin{tabular}{|c|c|c|c|}
\hline Distribution of G types & $\begin{array}{c}2005-2006^{a} \\
n=223\end{array}$ & $\begin{array}{c}2006-2007^{b} \\
n=156\end{array}$ & $\begin{array}{c}2007-2008^{c} \\
n=101\end{array}$ \\
\hline G1 & $57(26 \%)$ & $21(13.5 \%)$ & $18(17.8 \%)$ \\
\hline G2 & $26(12 \%)$ & $31(20 \%)$ & $9(9 \%)$ \\
\hline G3 & $4(2 \%)$ & $1(1 \%)$ & $10(9.9 \%)$ \\
\hline G9 & $15(7 \%)$ & $43(28 \%)$ & $23(22.8 \%)$ \\
\hline G12 & $112(50 \%)$ & $46(29 \%)$ & $34(33.7 \%)$ \\
\hline Non typeable* & $9(4 \%)$ & $14(9 \%)$ & $7(7 \%)$ \\
\hline
\end{tabular}

Note: a: November, 2005- October, 2006, b: November, 2006- October, 2007

November, 2007- October, 2008; * Strains could not be typed by this method.

Table 2: Distribution of rotavirus $P$ types among rotavirus-positive specimens of hospitalized children

\begin{tabular}{|c|c|c|c|}
\hline Distribution of $P$ types & $\begin{array}{c}2005-2006^{a} \\
N=223\end{array}$ & $\begin{array}{c}2006-2007^{b} \\
N=156\end{array}$ & $\begin{array}{c}2007-2008^{c} \\
N=101\end{array}$ \\
\hline$P[4]$ & $22(10 \%)$ & $37(24 \%)$ & $19(18.8 \%)$ \\
\hline $\mathrm{P}[6]$ & $83(37 \%)$ & $51(33 \%)$ & $28(27.7 \%)$ \\
\hline $\mathrm{P}[8]$ & $104(47 \%)$ & $54(35 \%)$ & $44(43.5 \%)$ \\
\hline mixed* & $4(2 \%)$ & $1(1 \%)$ & $2(2 \%)$ \\
\hline Non typeable ${ }^{* *}$ & $10(4 \%)$ & $13(8 \%)$ & $8(8 \%)$ \\
\hline
\end{tabular}

Note: a: Nov. 2005- Oct. 2006, b: Nov. 2006- Oct. 2007, C: Nov. 2007- Oct. 2008

*Mixed, specimens containing more than one $P$ genotype.

** Strains could not be typed by this method. 
Table 3: Distribution of major combination of $G$ and $P$ types among rotavirus-positive specimens of hospitalized children

\begin{tabular}{|c|c|c|c|}
\hline $\begin{array}{c}\text { Distribution of } \mathrm{G} \text { and } \mathrm{P} \\
\text { types }\end{array}$ & $\begin{array}{c}2005-2006^{a} \\
N=223\end{array}$ & $\begin{array}{c}2006-2007^{b} \\
N=156\end{array}$ & $\begin{array}{c}2007-2008^{c} \\
N=101\end{array}$ \\
\hline G1P[6] & $0(0 \%)$ & $0(0 \%)$ & $4(4 \%)$ \\
\hline G1P[8] & $52(23 \%)$ & $18(12 \%)$ & $12(11.9 \%)$ \\
\hline G2P[4] & $21(9 \%)$ & $31(20 \%)$ & $16(15.9 \%)$ \\
\hline G9P[8] & $14(6 \%)$ & $27(17 \%)$ & $1(1 \% \%)$ \\
\hline G9P[6] & $1(0)$ & $9(6 \%)$ & $2(1.9 \%)$ \\
\hline G12P[6] & $75(34 \%)$ & $38(24 \%)$ & $48(47.5 \%)$ \\
\hline G12P[8] & $31(14 \%)$ & $5(3 \%)$ & $3(3 \%)$ \\
\hline Other* & $8(4 \%)$ & $9(6 \%)$ & $3(3 \%)$ \\
\hline Mixed $^{* *}$ & $4(2 \%)$ & $1(1 \%)$ & $1(1 \%)$ \\
\hline Non typeable ${ }^{* * *}$ & $17(8 \%)$ & $18(12 \%)$ & $11(10.9 \%)$ \\
\hline
\end{tabular}

Note: a: November, 2005- October, 2006, b: November, 2006- October, 2007;

C: November, 2007- October, 2008

${ }^{*}$ Others include genotyping combinations other than broken down above.

${ }^{* *}$ Mixed, specimens containing more than one P genotype.

${ }^{* * *}$ Strains could not be typed by this method.

Of combined genotypes, G12P [6] was the most prevalent accounting $34 \%$ of strains in 2005-06, $24 \%$ in $2006-07$ and $47.5 \%$ in $2007-08$, followed by G1P [8] (23\%) in 2005-06 and G2P [4] (20\%) in 2006-07 15.9\% in 2007-08 table (3). Some of them are non typable $8 \%, 12 \%$ and $10.9 \%$ in each year $2006-08$, where as some of them are mixed type $2 \%, 1 \%$ and $1 \%$ each year respectively. There were some other genotype rather than $\mathrm{G}$ and $\mathrm{P}$ type were also seen I.e. $4 \%, 6 \%$ and $3 \%$ in each year 2006-08 respectively.

\section{Discussions}

Diarrheal disease remains one of the largest health problems in many parts of the world ${ }^{4,5,6,9}$. Studies in developing countries have shown that children in the first 2 years of the life may have up to 10 episodes of diarrheal disease, often with significant mortality ${ }^{10,11}$. Diarrheal disease occupied the second place among the top ten diseases in $\mathrm{Nepal}^{12}$.

The prevalence of rotavirus was $36.6 \%$ in hospital admitted patients. Fever and vomiting were significantly associated with rotavirus infection compared to other causes of diarrhea. In this study, of the total 1185 cases having abdominal pain with $38.31 \%$ rotavirus positive, 873 with fever with $36.42 \%$ rotavirus positive, 977 with nausea and vomiting with $41.76 \%$ rotavirus positive were seen. It was also known that rotavirus usually dominate in hospital based survey in children ${ }^{14,15,16}$. Rotavirus infection is commonly prevalent between age group 0-5 $\mathrm{yrs}^{6,14,15,17}$. Rotavirus was a major cause of pediatric gastroenteritis and responsible for causing half of the cases to be suffered with acute diarrheal illness among hospitalized patients of 6-24 months of age ${ }^{18}$. Similarly, this study showed that the infection rate was found to be higher in age group 3-23 months. In the present study, a clear seasonal pattern in rotavirus diarrhea was seen. Rotavirus infection occurred all year round but peaked during the fall and winter months, from December to March. Our results are similar to those of studies conducted in Korea, China, and Thailand but differed from those of a Japanese study, in which rotavirus was rarely detected from September to December ${ }^{5,17}$.

Three year (2005-2008) data of RT-PCR genotyping showed that G12 strains as the most prevalent Genotype; accounting for one- half of circulating rotavirus detected which was consistent with the preceding studies ${ }^{9,19,20,21}$, where as detection of other $\mathrm{G}$ genotypes changed more markedly over time. Similarly, serotype G1 and G9 was the second most common serotype found in the study periods. Serotype G9 has also emerged as one of the common types in other countries during the recent years $^{22}$. Similarly, of the three different P-types, P[8] was predominant in all year followed by $\mathrm{P}[6]$. Of combined genotypes, G12P [6] was the most prevalent accounting in all year. This showed that many different rotavirus types circulate simultaneously, particularly in developing countries. In addition, the prevailing types may differ considerably from one season to the next, even within the same geographical area. The type of rotavirus does not usually correlate with the severity of the disease $e^{17,20}$.

Despite the overall predominance of G12 strains, there were a total of 13 different $G$ and $P$ genotype combinations observed during 3 years period, of which G12P[6], G1P[8], G2P[4], and G9P[8], together accounted up to $75 \%$ of the rotavirus-positive 
specimens (Table 3). Although the relative frequency of each of the major $G$ and $P$ combinations of rotavirus strains circulating in Nepal varied in the previous two studies $^{9,19}$ and the current study, G12P[6], G12P[8], G1P[8], G2P[4], and G9P[6] rotavirus were all detected, indicating that there existed a large genetic pool of rotavirus genotypes in Nepal. In 2008 G1P [6] was found $4 \%$ which was not detected in 2006 and 2007.

Of rotavirus-positive samples, $4-9 \%$ remained untypeable for $G$ type, $4-8 \%$ for $P$ type and $8-12 \%$ for both $G$ and $P$ types. This could be due to few virus particles with intact RNA in the stool specimens, or the viruses not belonging to genotypes included in the primer set in RT-PCR.

\section{Conclusion}

The study demonstrates that rotavirus is the most prevalent causes of diarrhea in children less than 5 years of age. Rotavirus strain, study is essential for disease control program with continued identification of the most common $\mathrm{G}$ and $\mathrm{P}$ serotypes circulating causing disease an important priority establish policy regarding future implementation of rotavirus vaccine in Nepal.

Acknowledgments: This study was performed under a collaborative agreement with the Program for Appropriate Technology in Health (PATH) and was funded in full or in part by the GAVI Alliance and Division of Molecular epidemiology-Nagasaki University, Japan.

Conflict of Interest: None of the authors have a conflict of interest.

Permission from the IRB: Yes

\section{References}

1. Mukherjee AK, Chowdhury P, Bhattacharya MK, Ghosh M, Rajendran K and Ganguly. Hospitalbased surveillance of enteric parasites in Kolkata. BMC Research Notes. 2009;2:1186-1756.

2. Odimayo MS, Olanrewaju WI, Omilabu SA and Adegboro B. Prevalence of Rotavirus-induced Diarrhoea among Children under 5 Years in Ilorin, Nigeria. J Tropic Pediatr. 2008;1465-3664.

3. Bresee J, Fang ZY, Wang B, Nelson EAS, Tam J, Soenarto Y, Wilopo SA, Kilgore P, Kim JS, Kang JO, Lan WS, Gaik CL, Moe K, Chen KT, Jiraphongsa C, Pongsuwanna Y, Man NV, Tu PV, Luan LT, Hummelman E, Gentsch JR, Glass R, and the members of the Asian Rotavirus Surveillance Network. First Report from the Asian Rotavirus
Surveillance Network. Emerging Infect Dis 2004; 10(6):988-995.

4. Cortese MM and Parashar UD. Prevention of Rotavirus Gastroenteritis Among Infants and Children Recommendations of the Advisory Committee on Immunization Practices (ACIP). Division of Viral Diseases, National Center for Immunization and Respiratory Diseases. 2009; 58:1057-5987.

5. Nguyen TV, Van PI, Huy CL, and Weintraub A. Diarrhea Caused by Rotavirus in Children Less than 5 Years of Age in Hanoi, Vietnam. J Clin Microbiol. 2004;42(12):5745-5750

6. Shariff M, Deb M and Singh R. A Study of Diarrhoea Among Children in Eastern Nepal with Special Reference to Rotavirus. Indian J Med Microbiol 2003;21(2):87-90.

7. Gouvea V, Glass RI, Wood P, Taniguchi K, Clark $\mathrm{HF}$, Forreter $\mathrm{B}$ et al. Polymerase chain reaction amplification and typing of rotavirus nucleic acid from stool specimens. J Clin Microbiol 1990; 28: 276-282.

8. Gentsch JR, Glass RI, Woods P, Gouvea V, Gorziglia M, Flores J, Das BK, Bhan, MK. Identification of group A rotavirus gene 4 types by polymerase Chain reaction. J Clin Microbiol 1992; 30:1365-1373.

9. Ryuichi U, Pandey BD, Sherchand JB, Ahmed K, Yokoo M, Nakagomi T, Cuevas LE, Cunliffe NA, Hart CA and Nakagomi O. Moloecular Epidemiology of Rotavirus diarrhea among children and adults in Nepal: Detection of $\mathrm{G} 12$ strains with $\mathrm{P}[6]$ or $\mathrm{P}$ [8] and a G11P[25] strain. J Clin Microbiol 2006; 44 (10):3499-3505.

10. Parashar UD, Gibson CJ, Bresee JS, and Glass RI. 2006. Rotavirus and Severe Childhood Diarrhea. Emerging Infect Dis 2006;12(2):304-306.

11. Black RE. Persistent diarrhoea in children in developing countries. Pediatr Infect Dis J 1993; 12: 751-761.

12. Maharjan A, Sherchand JB, Pradhan B, Paudyl A and Pant AR. Rotavirus infection among diarrhoeal children attending Kanti children's hospital, Kathmandu, Nepal. J Nepal Health Res Council, 2006;4:34-40.

13. Anathnarayan $\mathrm{R}$ and Paniker JCK. Textbook of Microbiology, $4^{\text {th }}$ edition, Chennai: Orient Longman. 1994 pp 609-15. 
14. Bresee J, Fang ZY, EAS Nelson BW, Tam J, Soenarto Y, Wilopo SA, Kilgore P, Kim JS, Kang JO, Lan WS, Gaik CL, Moe K, Chen KT, Jiraphongsa C, Pongsuwanna Y, Man NV, Tu PV, Luan LT, Hummelman E, Gentsch JR, Glass R, and the members of the Asian Rotavirus Surveillance Network. First Report from the Asian Rotavirus Surveillance Network. Emerging Infec Dis 2004; 10(6):3390-3399.

15. Sherchand JB, Larsson $S$ and Rana BJ. On the incidence of rotavirus and enteric Adenovirus diarrhoea in children attending the out patient department of Kanti Children's Hospital and general practitioner in the Kathmandu area, J Nepal Med Assoc 1992;30:149-53.

16. Shrestha S, Upadhyay B, Limbu B, Pradhan R, Nakagomi T, Thorson S, Pollard AJ, Adhikari N. Rotavirus and its Genotype Distribution among Children Less than Three Years Presenting with Acute Watery Diarrhoea to a General Hospital in Urban Nepal. J Nepal Paediatr Soc 2010;31(2): 110-115.

17. Intusoma $U$, Sornsrivichai $V$, Jiraphongsa $C$, Varavithaya W.Epidemiology, Clinical Presentations and Burden of Rotavirus Diarrhea in Children under Five Seen at Ramathibodi Hospital, Thailand. J Med Assoc Thai 2008;91:1350-55.
18. WHO (2009). Introduction of rotavirus vaccine into national immunization programme. $\mathrm{CH}-1211$ Geneva 27, Switzerland.

19. Pun SB, Nakagomi T, Sherchand JB, Pandey BD, Cuevas LE, Cunliffe NA and Nakagomi O. Detection of G12 Human Rotavirus in Nepal. Emerging Infect Dis 2007;13:482- 484.

20. Sherchand JB, Nakagomi O, Dove W, Nakagomi T, Yokoo M, Pandey BD, Cuevas LE, CA Hart and Cunlifle NA. Molecular epidemiology of Rotavirus diarrhoea among children aged $<5$ years in Nepal: Predominance of emergence G12 during 2 years. $J$ Infect Dis 2009;200:4222-4228.

21. Shrestha S, Upadhyay B, Limbu B, Pradhan R, Nakagomi T, Thorson S, Pollard AJ, Adhikari N. Rotavirus and its genotype distribution among children less than three years presenting with acute watery diarrhea to a general hospital in Urban Nepal. J Nep Paedtr Soc. 2011;31:110-115.

22. Kheyami AM, Nakagomi T, Nakagomi O, Dove W, Hart CA, Cunliffe NA. Molecular epidemiology of rotavirus diarrhea among children in Saudi Arabia: first detection of G9 and G12 strains. J Clin Microbiol. 2008;46:1185-91.

\section{How to cite this article?}

Sherchand JB, Cunliffe NA, Tandukar S, Yokoo M, Pandey BD, Niraula P, Panta AR, Nakagomi O. Rotavirus disease burden and molecular epidemiology in children with acute diarrhea aged under 5 years in Nepal. J Nepal Paediatr Soc 2011;31(3):209-215. 